\title{
EDUCAÇÃO EM SAÚDE DE PUÉRPERAS EM ALOJAMENTO CONJUNTO NEONATAL: AQUISIÇÃO DE CONHECIMENTO MEDIADO PELO USO DE UM JOGO EDUCATIVO ${ }^{1}$
}

\author{
Luciana Mara Monti Fonseca ${ }^{2}$ \\ Carmen Gracinda Silvan Scochi ${ }^{3}$ \\ Débora Falleiros de Mello ${ }^{3}$
}

Fonseca LMM, Scochi CGS, Mello DF. Educação em saúde de puérperas em alojamento conjunto neonatal: aquisição de conhecimento mediado pelo uso de um jogo educativo. Rev Latino-am Enfermagem 2002 março-abril; 10(2):166-71.

O estudo objetiva verificar a aquisição de conhecimento nas atividades de educação em saúde, mediada pela utilização de um jogo educativo sobre aleitamento materno e cuidados básicos com o recém-nascido, em alojamento conjunto. Estudo realizado em uma maternidade filantrópica de Ribeirão Preto-SP. Atividades educativas foram realizadas em grupo, coordenadas pela enfermeira, utilizando jogo de tabuleiro. Por meio de entrevista estruturada, orientada por um roteiro pré e pós-jogo, verificamos a aquisição de conhecimento, classificando as respostas em insuficiente (0-4), regular (5-9), bom (10-14) e ótimo (15-20). Do conhecimento prévio das mães, 16,7\% de respostas foram ótimas, aumentando para $77,8 \%$ após participação da atividade educativa. Concluímos que o jogo constituiu estratégia adequada para facilitar troca de experiências entre puérperas e o desenvolvimento da educação em saúde por meio de atividades lúdico-pedagógicas.

DESCRITORES: enfermagem materno-infantil, alojamento conjunto, educação em saúde, jogos e brinquedos

\section{HEALTH EDUCATION OF PUERPERAS IN NEONATAL ROOMING-IN: ACQUISITION OF KNOWLEDGE MEDIATED BY THE USE OF AN EDUCATIONAL GAME}

The study aims at verifying knowledge acquisition through health education activities mediated by the use of an educational game on breast-feeding and basic care provided to the newborn, in rooming-in. Study accomplished at a philanthropic maternity of Ribeirão Preto-SP. Educational activities were accomplished in group, coordinated by the nurse, using board game. Through structured interview guided by a route before and after-game, the authors verified the knowledge acquisition, classifying the answers in insufficient (0-4), regular (5-9), good (10-14) and excellent (15-20). Of the mothers' previous knowledge, 16,7\% of answers were excellent increasing for $77,8 \%$ after participation in the educational activity. They concluded that the game constituted in appropriate strategy to facilitate change of experiences between puerperas and the development of the health education through ludic-pedagogical activities.

DESCRIPTORS: maternal-infant nursing, rooming-in, health education, game and toys

\section{LA EDUCACIÓN EN SALUD DE PUÉRPERAS EN ALOJAMIENTO CONJUNTO NEONATAL: LA ADQUISICIÓN DE CONOCIMIENTO POR INTERMEDIO DE UN JUEGO EDUCATIVO}

El estudio pretende verificar la adquisición de conocimiento en las actividades de educación en salud intermediadas por el uso de un juego educativo sobre lactancia materna y cuidados básicos con el recién nacido, en un alojamiento conjunto. El estudio se realizó en una maternidad filantrópica de Ribeirão Preto-SP. Las actividades educativas fueron realizadas en grupo, coordinadas por la enfermera, usando el juego en el tablero. A través de entrevista estructurada con una guía antes y después de-juego, verificamos la adquisición de conocimiento, clasificando las respuestas en insuficiente (0-4), regular (5-9), bueno (10-14) y excelente (15-20). 16,7\% de respuestas fueron excelentes, aumentando para el $77,8 \%$ después de la participación en la actividad educativa. Concluimos que el juego constituyó una estrategia apropiada para facilitar el cambio de experiencias entre las puérperas y el desarrollo de la educación en salud a través de actividades lúdico-pedagógicas.

DESCRIPTORES: la lactancia del maternal-infante, alojar-en, la educación de salud, el juego

\footnotetext{
${ }^{1}$ Trabalho apresentado no VI Congresso Brasileiro de Saúde Coletiva. 2000/Salvador, Bahia, Brasil; ${ }^{2}$ Enfermeira, Mestranda do Programa de Pós-Graduação Enfermagem em Saúde Pública; ${ }^{3}$ Professor Doutor, e-mail: cscochi@eerp.usp.br, da Escola de Enfermagem de Ribeirão Preto da Universidade de São Paulo, Centro Colaborador da OMS para o desenvolvimento da pesquisa em enfermagem
} 
INTRODUÇÃO

alojamento conjunto tem como objetivo a integração mais íntima da mãe com o recém-nascido (RN), contribuindo para: estabelecer um relacionamento afetivo favorável entre mãe-filho, desde o nascimento; educar a mãe e o pai, desenvolvendo habilidades e proporcionando segurança emocional quanto aos cuidados com 0 bebê; incentivar 0 aleitamento materno; reduzir a incidência de infecções hospitalares cruzadas; permitir à equipe de saúde melhor integração e observação sobre o comportamento normal do binômio mãe-filho ${ }^{(1)}$.

Permite, ainda, uma renovação dos profissionais da saúde no seu contexto de atuação, pois, dentro de um novo e mais amplo conceito de saúde materno-infantil, o ato de curar e cuidar não é atividade exclusivamente dos profissionais da saúde, mas inclui a co-participação daquele que é tratado e curado. Essa acepção, oriunda do espírito da Pediatria Social, transforma o setor de maternidade de agência de assistência técnica de manutenção da saúde em centros de educação sanitária de longo alcance. A mãe, ensinada a se cuidar, a entender o filho, a satisfazer suas necessidades integrais, torna-se agente multiplicador da saúde em âmbito individual, familiar, social e ecológico.

Dentre as vantagens desse sistema, enfatizamos a educação em saúde, constituindo-se em centro natural de educação e não um local de acomodação de pessoas. Nesse sentido, 0 Ministério da Saúde argumenta que o alojamento conjunto não é um método de assistência utilizado para economizar pessoal de enfermagem, pois tem um alto conteúdo educativo que precisa ser considerado prioritário ${ }^{(1)}$.

Assim, durante o tempo de permanência no hospital, é vantajoso que a mãe e o pai participem do cuidado do bebê, sob orientação direta da enfermeira. Todavia, nem todas as maternidades desenvolvem atividades educativas regularmente. Em um estudo, em que analisam o trabalho em duas maternidades do município de Ribeirão Preto-SP, os autores constataram que, na instituição privada, não havia ações educativas sistematizadas, pois elas dependiam das peculiaridades das atendentes ou auxiliares de enfermagem, sendo que a maioria demonstrou um trabalho normativo, mecanizado, inespecífico e, de certa forma, autoritário. Na instituição pública, havia intervenções educativas sistematizadas, os trabalhadores de enfermagem faziam orientações individuais ou em pequenos grupos sobre os cuidados básicos com o RN. Verificaram, também, inadequações e deficiências quantitativas nas atitudes e capacitação dos profissionais de saúde para manejarem as inter-relações com a clientela, sendo recomendado um esforço das instituições de ensino e assistenciais para capacitação dos recursos humanos, instrumentalizando-os com conhecimentos sobre interação mãe-filho, relações familiares e técnicas educativas, a fim de desenvolverem habilidades para a atenção integral à saúde ${ }^{(2)}$.

Sabendo da importância da educação em saúde no alojamento conjunto, consideramos que, na prática cotidiana, há espaço para desenvolvimento de atividades criativas, visando à melhoria da qualidade do cuidado de enfermagem.

Nessa perspectiva é que nos sentimos estimuladas a desenvolver estratégias criativas na educação em saúde de puérperas em alojamento conjunto. Vislumbrando a possibilidade de construir, com a mãe, conhecimentos acerca dos cuidados com o RN e o aleitamento materno. Num esforço para o preparo mais adequado da alta hospitalar, elaboramos um jogo educativo para instrumentalizar nossa prática educativa.

Assim, motivamo-nos a realizar o presente estudo, cujo objetivo é verificar a aquisição de conhecimento proporcionado pela utilização do jogo educativo, tendo por base nossa vivência no desenvolvimento e utilização de material didático-pedagógico inovador, para facilitar e dinamizar o processo de ensinoaprendizagem junto às puérperas. Esperamos, com isso, fornecer subsídios para a organização da prática de enfermagem em alojamento conjunto, através da utilização de tecnologia simplificada em atividades educativas, rumo ao processo de construção de uma assistência integral mais criativa e participativa.

\section{MÉTODOS}

O estudo foi realizado em uma maternidade filantrópica do município de Ribeirão Preto-SP, a qual possui 44 leitos de alojamento conjunto e destina-se à assistência ao parto de baixo risco da clientela usuária do Sistema Único de Saúde. A permanência da clientela nessa maternidade é curta, em torno de 24 horas após o parto. É campo de estágio de alunos de graduação em enfermagem e constitui local onde os docentes da Escola de Enfermagem de Ribeirão Preto, da Universidade de São Paulo, desenvolvem atividades de extensão de serviços à comunidade.

Para aprimorar as atividades de educação em saúde, criamos um jogo educativo para discussão, em grupos de puérperas, de temas relacionados à amamentação, como cuidados com as mamas, traumas mamilares e direitos da mãe que trabalha, bem como conteúdos relativos aos cuidados com o RN como curativo do coto umbilical, higiene corporal, banho de sol, vestuário, teste do pezinho, cólica e choro. As questões que direcionam a atividade lúdico-pedagógica abordam essas temáticas de maneira mais diretiva ou indiretamente, ao conterem afirmações ou questionamentos sobre alguns mitos presentes no cuidado do bebê. Além disso há um tabuleiro colorido, com percurso dividido em 26 caselas, tendo ponto 
de saída e de chegada dos jogadores; 50 cartas contendo perguntas sobre as temáticas citadas e, no verso, as respectivas respostas; dois dados e peões coloridos representando cada jogador ou dupla. 0 número mínimo de jogadores é 4, e o máximo, 12, formando-se duplas, caso o número de jogadores seja superior a $5^{(3)}$.

Na dinâmica, cada participante ou dupla retira uma carta e, se acertar a questão, caminha no tabuleiro o número de casas correspondente à soma de pontos obtida no lançamento dos dados. Ganha o jogo aquela(s) que chegar(em) primeiro ao final do percurso. Estimula-se participação de outras mães para completarem as respostas às questões formuladas.

Neste estudo, a amostra constituiu-se das participantes em 2 grupos de atividade educativa, 16 puérperas e 2 pais, na faixa etária de 17 a 31 anos, sendo a moda de 21 a 25 anos.

0 nível de escolaridade variou desde o primeiro grau incompleto até 0 ensino médio completo. $O$ número de filhos variou de 1 a 7 , sendo que a maioria (7) era primípara.

Para verificar a aquisição de conhecimentos proporcionada pelo jogo educativo, os dados foram coletados através de entrevista estruturada (ANEXO), orientada por um roteiro, pré e pós-jogo. 0 roteiro pré-jogo e pós-jogo continha 10 perguntas sobre aleitamento materno e 10 sobre cuidados com o RN. As respostas foram categorizadas em certas e erradas, sendo o conhecimento geral de cada puérpera classificado em insuficiente, regular, bom e ótimo ao apresentar respostas corretas nos seguintes intervalos: até 4 , de 5 a 9,10 a 14 e 15 a 20.

As entrevistas com as puérperas foram realizadas mediante esclarecimento sobre os objetivos da pesquisa, solicitação de sua participação e consentimento, garantindo sigilo, além de serem informadas a respeito de sua liberdade em se recusar a participar ou retirar seu consentimento em qualquer fase da pesquisa, sem penalização alguma. Após terem ciência do exposto acima, os que aceitaram participar assinaram um termo de consentimento; para as adolescentes obtivemos também autorização do responsável.

\section{RESULTADOS E DISCUSSÃO}

A atividade lúdico-pedagógica desenvolvida para puérperas foi idealizada a partir da necessidade de passar informações de forma dinâmica, com a participação efetiva delas na construção dos seus conhecimentos. As atividades educativas foram realizadas em grupo, coordenadas pela enfermeira, e tiveram duração média de uma hora.

Em estudo anterior, objetivando descrever e analisar a opinião das mães e a percepção do profissional enfermeiro sobre as atividades de educação em saúde mediadas pelo uso do jogo educativo, constatamos que as mães, frente ao jogo, ficavam mais descontraídas; as mais tímidas eram, estimuladas por nós a expor suas experiências passadas, positivas e negativas. 0 fato de as outras participantes relatarem suas experiências fez com que as tímidas se sentissem à vontade para se colocar também. Quando começavam a abordar sobre as dúvidas, que sentiam vergonha de exteriorizar, e percebiam que essas eram também de outras participantes, elas se sentiam mais à vontade para colocá-las para o grupo. Estimulamos a obtenção de respostas às perguntas formuladas a partir da experiência do próprio grupo, dos conhecimentos obtidos da relação com as suas próprias mães e sogras, vislumbrando a elucidação de problemas e tabus a partir do seu próprio meio, da realidade que as cerca. Os comportamentos de risco para o auto-cuidado e o cuidado com o RN eram discutidos, reforçando as atitudes positivas, verbalizadas por algumas puérperas ${ }^{(4)}$.

Essa experiência oportunizou-nos desenvolver a atividade de educação em saúde, de maneira descontraída e criativa, utilizando recursos não usuais dessa prática, estimulando a participação efetiva tanto das puérperas como de outros profissionais (residentes, enfermeiros e alunos de enfermagem) que percebiam as mães demonstrando e verbalizando os benefícios de aquisição de conhecimento e a descontração após a participação na atividade educativa ${ }^{(4)}$.

Depreendemos, ainda, neste estudo, durante a execução das atividades educativas, atitudes de descontração das participantes. Antes da criação desse jogo, essa atividade era monótona, desestimulante, repetitiva, tornando-a desinteressante para 0 educador/enfermeiro. Atualmente, sentimo-nos empenhadas e motivadas para desenvolver essa prática, utilizando uma estratégia que permite a participação do grupo na criação do conhecimento ${ }^{(4)}$. Um outro estudo também fez uma avaliação positiva sobre a utilização do jogo educativo, pois percebeu que as puérperas ficavam mais abertas a expor suas duvidas e o que tinham apreendido ${ }^{(5)}$.

Os jogos educativos, do ponto de vista estrutural, têm grande importância para a produção do conhecimento. $O$ sentido e a necessidade de teoria (do esforço humano de explicar as coisas, de dar respostas ainda que provisórias para as perguntas que nos faz 0 jogo da vida) formulam-se e ganham contexto nos jogos. De certo modo, as fantasias, as mitificações, os modos deformantes de pensar ou inventar a realidade são como prelúdio para futuras teorizações. Em síntese, para esse autor, os jogos são a base para o como e 0 porquê das coisas ${ }^{(6)}$.

Em nosso estudo, constatamos que a atividade educativa mediada pelo uso de um jogo contribuiu para aquisição de conhecimento sobre amamentação materna e cuidados com o RN. A Tabela 1 mostra aumento significativo na proporção de puérperas com conhecimento "Ótimo" no pós-jogo e ausência da classificação "Regular". 
A tabela a seguir mostra, a distribuição do conhecimento das puérperas sobre 0 aleitamento materno e cuidados com o RN antes e após participação na atividade educativa por meio do jogo.

Tabela 1 - Conhecimento das puérperas, antes e após o jogo

\begin{tabular}{ccc}
\hline CONHECIMENTO & PRÉJJOGO & PÓSJJOGO \\
\hline Insuficiente & -- & -- \\
Regular & $01(5,5 \%)$ & -- \\
Bom & $14(07,6 \%)$ & $04,22,2 \%)$ \\
Ótimo & $03(16,7 \%)$ & $14(07,0 \%)$ \\
TOTAL & $18(100 \%)$ & $18(100 \%)$ \\
\hline
\end{tabular}

Da análise das respostas maternas sobre amamentação, constatamos que 11 (61,1\%) puérperas apresentaram conhecimento "Ótimo" sobre as 10 perguntas formuladas na entrevista pré-jogo, e 7 (38,8\%), "Bom". Após participarem da atividade educativa, essa distribuição eleva-se para 16 (88,8\%) com conceito "Ótimo"; 2 (11,1\%) puérperas demonstraram conhecimento "Bom" no pós-jogo, nas questões sobre aleitamento materno.

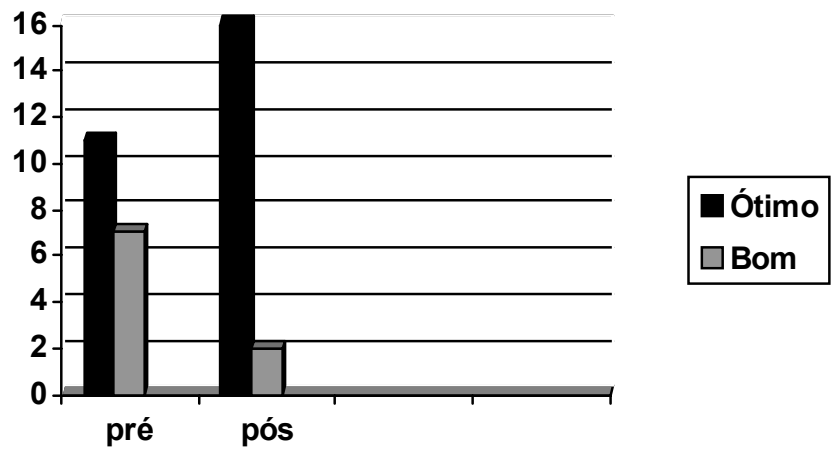

Figura 1 - Conhecimento sobre amamentação pré e pós-jogo educativo

$\mathrm{Na}$ entrevista pré-jogo, 10 perguntas sobre os cuidados com o RN, 11 (61,1\%) participantes receberam conceito "Bom", e 7 $(38,8 \%)$ receberam "Regular". No pós-jogo, $11(61,1 \%)$ participantes receberam conceito "Ótimo", 6 (33,3\%), "Bom”, e 1 (5,5\%), "Regular".

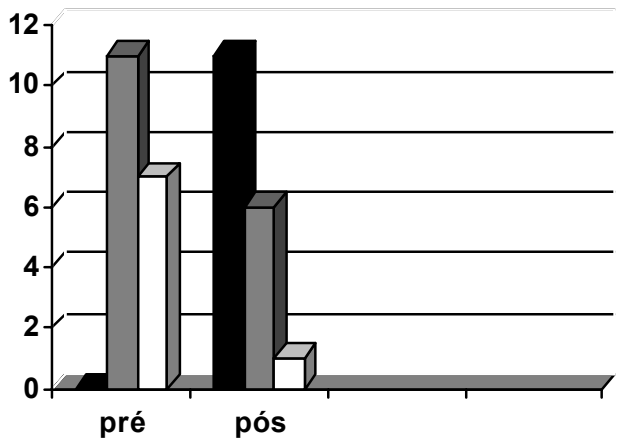

\begin{tabular}{|l|}
$\square$ Ótimo \\
$\square$ Bom \\
$\square$ Regular
\end{tabular}

Figura 2 - Conhecimento sobre os cuidados com o RN pré e pósjogo educativo
Ao participarem da atividade e terem acesso às informações e aos "porquês", as mães expressaram que não haviam, em tempo algum, perguntado o "porquê" das orientações recebidas, o que as tornava meras cumpridoras de ordens.

Isto nos remete a pensar na verticalização e dominância em que se apresentam os programas de educação em saúde, vindos com o surgimento da puericultura, no século XIX, em que a assistência à saúde da criança não enfatizava a participação da mãe no cuidado; eram dadas ordens às mães, na tentativa de doutriná-las. Nesse contexto, a educação em saúde assume o papel de transmissora de conhecimento - "dos que sabem" "para os que não sabem" (pedagogia tradicional).

Em contraponto à "pedagogia tradicional", centramos nosso estudo na pedagogia moderna - teoria construtivista, no qual o aprendiz é o agente ativo do seu próprio conhecimento.

Durante muito tempo, confundiu-se "ensinar" com "transmitir" $e$, nesse contexto, o indivíduo que aprendia era um agente passivo da aprendizagem, e o que ensinava era um transmissor não necessariamente presente nas necessidades do aprendiz. Atualmente, sabe-se que não existe ensino sem que ocorra a aprendizagem e que esta não acontece senão pela transformação, pela ação facilitadora do ensinador e pelo processo de busca do conhecimento, que deve sempre partir do aprendiz. A idéia de um ensino despertado pelo interesse do aprendiz acabou transformando o sentido do que se entende por material pedagógico, e cada aprendiz, independente de sua idade, passou a ser um desafio à competência do ensinador; o ensinador passou a ser um gerador de situações estimuladoras e eficazes. É nesse contexto que o jogo ganha um espaço como ferramenta ideal da aprendizagem, na medida em que propõe estímulo ao interesse do aprendiz. 0 jogo ajuda-o a construir suas novas descobertas, desenvolve e enriquece sua personalidade e simboliza um instrumento pedagógico que leva ao ensinador a condição de condutor, estimulador e avaliador da aprendizagem ${ }^{(7)}$.

No envolvimento das puérperas na atividade educativa no alojamento conjunto, houve troca de experiências acerca dos temas em discussão; a "brincadeira" e "o jogar" garantiram a liberdade verbal, diminuindo o medo de se expor.

É importante registrar que a riqueza do conteúdo discutido durante o jogo provém de experiências anteriores, adquiridas pelas participantes, em diferentes contextos. A aquisição de idéias e ações provêm do mundo social, incluindo a família e o círculo de relacionamentos. Os conteúdos veiculados durante o jogo, paralelos às cartas (perguntas formuladas), bem como as oportunidades para interações sociais são todos fatores que dependem basicamente de cada grupo e do profissional que o conduz.

É necessário atender às necessidades de aprendizagem do adulto, abordando a importância de usar estratégias de ensino 
que aproveitem ao máximo as experiências anteriores das pessoas, dando ênfase à participação e ao envolvimento ativo dos educandos. Segundo esta autora, as enfermeiras educadoras devem dar menos respostas e fazer mais perguntas para que, no educando, o processo intelectual seja estimulado. Considera o jogo como uma estratégia que pode atingir essa finalidade ${ }^{(8)}$.

Várias enfermeiras têm escrito sobre esse tema, demonstrando que a utilização do jogo no ensino promove interação e envolvimento entre os participantes, estimula interesse em um determinado tópico e provê elementos para mudança de atitude ${ }^{(9-10)}$.

Há outros estudos recentes sobre jogos como estratégia de ensino a serem utilizadas pelas enfermeiras educadoras. Os autores selecionaram um jogo como estratégia de ensino por considerá-lo um processo interativo que facilita a aquisição e aplicação de conhecimentos e habilidades cognitivas, afetivas e psicomotoras ${ }^{(11-}$ 13)

A oportunidade para discussão durante o jogo aumenta 0 interesse e a motivação, facilita a assimilação de conceitos pela estimulação do processo cognitivo, permite a expressão de opiniões, esclarece conceitos, reforça e suplementa aprendizagem e promove positiva aprendizagem afetiva ${ }^{(14)}$.

\section{CONCLUSÕES}

Por meio dos resultados, apreendemos que o jogo

\section{ANEXO}

\section{INSTRUMENTO DE AVALIAÇÃO PRÉ E PÓS-JOGO}

A - Com base nos seus conhecimentos acerca do aleitamento, responda se estão certas ou erradas as questões abaixo:

1. O aleitamento materno deve ser evitado, pois o seio da mãe fica "caído". Certo ( ) errado ( )

2. É importante amamentar o bebê no peito, pois oferece proteção a ele contra várias doenças, diminui as chances de a mãe ter câncer de mama, além de promover uma relação amorosa entre mãe e filho. Certo ( ) errado ()

3. É o bebê quem faz o horário das mamadas e ele deve mamar até ficar satisfeito. Certo( ) errado ( )

4. Logo que o bebê nasce, o leite é amarelado e forte, com o passar dos dias, ele se torna ralo e fraco. Certo ( ) errado ( )

5. Mamando só no peito, se o bebê apresentar fezes bem amolecidas, será necessário suspender as mamadas e procurar o médico. Certo ( ) errado ( ) 6 . Se o leite empedrar, você deverá fazer massagens circulares nos lugares de endurecimento e retirar a sobra do leite toda vez que sentir o peito muito educativo, enquanto uma nova estratégia para educação em saúde, contribuiu para ampliar o conhecimento das mães sobre a relevância do aleitamento materno, o autocuidado com a mama puerperal e os cuidados básicos com o RN. Houve troca de experiências entre os participantes, aquisição de conhecimentos e abertura para discussão de mitos e atitudes de risco para a saúde da puérpera e do bebê.

Todavia, a metodologia utilizada não assegura mudanças dos comportamentos de risco das mães, dada a complexidade de fatores envolvidos nesse processo.

Acreditamos que o estudo pode contribuir com o preparo técnico dos profissionais de saúde com vistas à assistência integral e humanizada, em alojamento conjunto, suscitando o desejo de ousar, de criar, partindo do pressuposto de que o jogo educativo aqui empregado apresenta tecnologia simplificada, artesanal, manufatura barata e acessível.

Cabe assinalar que a nossa experiência de intervenção, embora válida, deve estar inserida em um projeto maior de educação em saúde a ser trabalhado pelos setores sociais envolvidos com a formação dos cidadãos. Vários aspectos das temáticas como aleitamento, maternidade/paternidade, autocuidado e cuidados com o bebê deveriam ser discutidos durante a escolarização, no planejamento familiar, pré-natal e seguimento na rede básica de saúde, na perspectiva do continuum da assistência no processo de crescimento e desenvolvimento do ser humano.

cheio, se o "bico" ficar dolorido ou se "rachar", tomar sol no local e passar pomadas. Certo( ) errado ( )

7. O bebê, mamando só no peito, precisa tomar água ou chá nos intervalos das mamadas. Certo ( ) errado ( )

8. Quando a auréola (rodela marrom do peito) está macia, o bebê "abocanha" melhor e isso previne a rachadura do mamilo. Certo ( ) errado ( )

9. Antes de dar de mamar ao bebê, não é necessário fazer coisa alguma com o peito. Certo ( ) errado ( )

10. 0 bebê que mama no peito não precisa de outros alimentos, porque 0 leite da mãe tem tudo de que ele necessita nos primeiros seis meses de vida. Certo ( ) errado ( )

B - Em relação aos cuidados com o bebê responda se estão certas ou erradas as questões abaixo:

1. É necessário dar banho no bebê todos os dias, mas não esfregar muito a "moleira" ao lavar a cabeça. Certo ( ) errado ( )

2. Para evitar assaduras, devemos trocar as fraldas freqüentemente, lavar bem o bumbum do bebê, toda vez que fizer "cocô" e passar bastante pomada e talco. Certo ( ) errado ( )

3. Pode-se usar qualquer tipo de fralda no bebê (pano, descartável ou calça 
plástica com fralda de pano), desde que as troque com freqüência. Certo () errado ()

4. 0 umbigo do bebê deve ser curado todos os dias, com pó anti-séptico para evitar que sangre e cause infecção, podendo aplicar azeite para que caia logo. Certo () errado ()

5. Todo bebê que mama no peito apresenta cólicas. É preciso dar chá de erva-doce com bastante açúcar nos intervalos das mamadas. Certo ( ) errado ()

6. Na primeira semana de vida do bebê, ele pode apresentar a pele o olhos amarelados, necessitando tomar sol de manhãzinha ou no final da tarde. Para isso é preciso colocá-lo "peladinho" ao sol, protegendo os olhos e evitando correntes de ar. Certo( ) errado()

\section{REFERÊNCIAS BIBLIOGRÁFICAS}

1.Ministério da Saúde (BR). I Encontro Nacional sobre Alojamento Conjunto. Relatório Final. Brasília: Ministério da Saúde/INAN; 1982. 2. Scochi CGS, Mello DF, Javorski M, Menossi MJ. $O$ alojamento conjunto em hospitais-maternidade do município de Ribeirão Preto: análise da assistência. Acta Paul Enfermagem 1996; 9(3):15-23.

3. Fonseca LMM, Scochi CGS. Inovando a assistência de enfermagem ao binômio mãe-filho em alojamento conjunto neonatal através da criação de um jogo educativo. Rev Latino-am Enfermagem 2000; 8(5):106-8.

4. Fonseca LMM, Scochi CGS, Bis CEF, Serra SOA. Utilizando a criatividade na educação em saúde em alojamento conjunto neonatal: opinião de puérperas sobre o uso de um jogo educativo. Rev Bras Enfermagem 2000; 53(2):301-10.

5. Frederico P, Fonseca LMM, Nicodemo AMC. Atividade educativa no alojamento conjunto: relato de experiência. Rev Latino-am Enfermagem 2000; 8(4):38-44.
7. É necessário banho de picão no bebê quando ele está "amarelinho". Certo ( ) errado ()

8. Se o bebê chora muito, quer dizer que está com fome, pois o leite está ralo elou secando. Certo ( ) errado ( )

9. 0 bebê pode chorar por estar com dor, com a fralda molhada ou suja de "cocô", estar com frio ou com calor, ou apenas querendo colo. Certo ( ) errado ()

10. $O$ bebê que chupa chupeta tem mais chance de ter sapinhos. Certo ( ) errado ()

Respostas do instrumento: A - certo: 2, 3, 8, 9, 10; errado: 1, 4, 5, 6, 7 e B certo: $3,6,9$, 10; errado: 1, 2, 4, 5, 7, 8 .

6. Macedo L. Os jogos e sua importância na escola. Cad Pesq 1995; 93:5-10.

7. Antunes C. Jogos para a estimulação das múltiplas inteligências. Petrópolis: Vozes; 1999.

8. Rosendahl P. Self-direction for learners: na andragogical approach to nursing education. Nurs Forum 1974; 13(2):136-46.

9. Alexander MA. Winning with games. Nurse Educ 1986; 11(5):5. 10. Silva JR, Deck ML. The games we play. J Pediatr Nurs 1989; 4(1):59-61.

11. Ulione MS. Simulation gaming in nursing education. J Nurs Educ 1983; 22(8):349-51.

12. Joos IRM. A teacher's guide for using games and simulation. Nurse Educ 1984; 9(3):25-9.

13. Kolb SE. North: a game for teaching concepts of patient care. Nurse Educ 1983; 8:12-5.

14. French P. Academic gaming in nurse education. J Adv Nurs 1980; 5(6):601-12. 